T. Matsusaka

Nagoya Math. J.

Vol. 36 (1969), 119

GORREGTION TO "ALGEBRAIC DEFORMATIONS

OF POLARIZED VARIETIES", NAGOYA

MATHEMATIGAL JOURNAL,

VOL. 31, 1968.

\title{
T. MATSUSAKA
}

There was an obvious error in $\left(P_{4}\right)$, p. 193. It should be corrected as follows:

$\left(P_{4}\right) \quad$ When $Y$ is a $V$-divisor, it is contained in $\mathfrak{X}$ if and only if there is a pair $(r, s)$ of integers not in $\mathfrak{M}$ such that $r Y \equiv s X \bmod \mathscr{S}_{a}$.

Brandeis University

Received January 22, 1969. 